\title{
EDITORIAL \\ TEMPOS DE CRISE, TEMPOS DIFÍCEIS E A ATUALIDADE E RELEVANCIA DOS ARTIGOS PUBLICADOS
}

TIMES OF CRISIS, HARD TIMES AND THE TIMELINESS AND RELEVANCE OF

PUBLISHED ARTICLES

TIEMPOS DE CRISIS, TIEMPOS DE DIFICULTADES, TIEMPOS DE PRODUCTIVISMO, LA ACTUALIDAD Y IMPORTANCIA DE LOS ARTÍCULOS PUBLICADOS.

Maurício Roberto da Silva

Editor

mauransilva@gmail.com

Miguel Ângelo Silva da Costa

Editor

miguel.costa@unochapeco.edu.br

REVISTA PEDAGÓGICA

Revista do Programa de Pós-graduação em Educação da Unochapecó | ISSN 1984-1566

Universidade Comunitária da Região de Chapecó | Chapecó-SC, Brasil

Como referenciar este artigo: SILVA, M. R. COSTA, M. A. S. C. Tempos de crise, tempos difícies e a atualidade e relevância dos artigos publicados. Revista Pedagógica, Chapecó, v. 16, n.32, p. 05-15, jan./jul. 2014.

\section{Currículo Lattes}

Esqueça os conceitos

Não pense em teorias

Ou categorias,

Esquemas já feitos

Pra mentes vadias...

O eterno, o perfeito,

Não cabe em conceitos!

Conceito é prisão

Da deusa Razão.

Metáforas são

Os vôos infinitos,

Fugindo a restritos

Grilhões-prisão

Da conceituação.

Ao templo de Ideias,

Prefiro alcatéias

De rimas ateias,

Que vêm e que vão,

No templo pagão

Da Imaginação.

Currículo Lattes?...

Não tinham os vates

Dos templos antigos.

Só têm os cientistas

Que amam as listas

De muitos artigos.

Heráclito e Thales.

\section{(}

São sábios sem "qualis"... Ao qualis e ao lattes, Prefiro bons mates, Os chopps com amigos, As pizzas e as massas, As cucas com passas De uvas e figos. Às sérias reuniões

Da academia,

Prefiro a poesia

Dos velhos galpões. Aos ritos da Ciência,

Prefiro a querência

Das trovas e causos. Aos pontos do qualis

Da deusa Razão,

Prefiro os aplausos Às rimas campeiras, Que em noites inteiras,

A imaginação Em versos tropeia, À luz da lua cheia E ao fogo de chão.

Pra praia me vô,

E assino: Baldô

(Balduíno Andreola) 


\section{Tempos difíceis, tempos de crise}

Produzir esta edição significa, mais uma vez, entre obstáculos estruturais e conjunturais, atualizar a periodicidade até dezembro de 2014. Durante a construção desse número, viemos acompanhando a crise política, econômica, educacional, cultural e ética que vem assolando o Brasil, mas também os diversos rincões do planeta. É um momento delicado que requer dos intelectuais um olhar profundo para poder entender as especificidades dos problemas da economia, da política e da educação no limiar da conjuntura nacional e suas possíveis relações com a crise instaurada na conjuntura internacional.

Produzir um projeto editorial, principalmente na área da educação, a nosso ver, não exime os editores de refletir sobre os problemas mais universais da conjuntura e, aliado a isso, os problemas da educação e suas políticas, que são determinadas pela lógica da mercantilização e precarização da educação, terminando por acentuar as desigualdades sociais e escolares.

O tempo difícil e de crise em que estamos imersos é de suma relevância para separar o joio do trigo, na perspectiva de fazer análises dialéticas, no sentido de poder apontar as possíveis relações entre os problemas da conjuntura nacional (equívocos de gestão, ataque às políticas sociais, precarização do trabalho e da educação, inflação, corrupção e outros pontos da agenda político-econômica). Nesses termos, vale questionar: em que medida os problemas engendrados pela crise estrutural, cíclica e destrutiva do capital em escala mundial reverberam na economia política brasileira? Dizemos isso porque sabemos que, conforme indicam estudiosos, a lógica da crise mundial do capital centra-se nos seguintes imperativos humano-societais: produção e consumo supérfluos, que acabam gerando a corrosão do trabalho (precarização e desemprego estrutural) e, por fim, a destruição da natureza em escala global (Mészáros apud Antunes, 2011, p. 11). A crise estrutural do capital, portanto, a partir de suas determinações neoliberais, é uma crise de dominação, que em seu sistema global conjuga-se com a sempre crescente articulação entre ciência e tecnologia, trabalho e educação (Mészáros, 2011, p. 54). Mas a pergunta se insurge outra vez: em que medida a crise do capitalismo pode desarticular, no âmbito das políticas públicas, a ciência da tecnologia e o trabalho da educação, e precarizá-los?

Realizar esse movimento de reflexão crítica torna-se imprescindível, sobretudo, em tempos de corrupção acumulada ao longo dos diversos mandatos dos governos brasileiros; em tempos de crise imposta pela avareza e pela gana de acumulação de capital cada vez mais desmedida, crise dos valores, crise das instituições, crise da política. Aliás, essas crises trazem consigo a necessidade de supera- 
ção da ideia que todos os políticos são corruptos e iguais. Ao invés disso, urge pensar com Milton Santos (2000, p. 29), ao lembrar que utopicamente "[...] o mundo não é somente constituído das coisas já feitas, mas de tudo o que é ainda possível realizar. A História não é apenas o que existe, mas também a soma dos possíveis."

É um momento de crise que anseia por propostas de mudanças de reforma política tributária, econômica, ética. Sendo assim, nós, intelectuais, que produzimos e socializamos conhecimento na área da Educação, devemos refinar nossas posições críticas, fazer autocrítica, fazer a negação e, essencialmente, a negação da negação, no sentido de buscar uma outra ética na política de viés superador e revolucionário. "Como uma luz no fundo do túnel", esses procedimentos nos impelem a construir novos rumos nos espaços da academia e fora dela, no intuito de analisar, para além do capitalismo neoliberal, o modo como economia e política vem sendo encaminhadas e suas repercussões nas políticas sociais e, fundamentalmente, nas políticas educacionais.

Com efeito, o Estado brasileiro precisa aplicar, urgentemente, políticas simultâneas de valorização dos trabalhadores da educação, estes constantemente em greve, garantindo a eles os seguintes pontos da agenda de lutas: a profissionalização com a formação inicial e continuada, a aplicação integral da lei do piso salarial profissional nacional, conforme o artigo 206 da Constituição Federal, aprovando e aplicando a lei de diretrizes de carreira para o conjunto da categoria. Deve investir na construção de novas escolas e melhorar a infraestrutura existente, para garantir condições adequadas ao processo de ensino-aprendizagem. Há de se desenvolver a vivência da gestão democrática, com um conselho escolar deliberativo e composto por representantes de todos os seguimentos da comunidade escolar e local, escolhidos pelas entidades representativas de cada um. E, ainda, aplicar políticas preventivas e curativas para cuidar da saúde dos profissionais. São medidas que vão garantir a permanência dos alunos matriculados e motivar a entrada nas escolas públicas das pessoas de quatro a 17 anos de idade que estão fora da educação básica (Revista Retratos da Escola, CNTE, 2013, p. 11). Todas essas medidas devem ser conquistadas, necessitando ser implementadas para tornar a Educação uma questão de Estado e um direito de todos os cidadãos.

Para que isso se materialize, temos que superar a ideia, conforme alguns grupos de esquerda fizeram, de avaliar a conjuntura logo após as eleições, a partir da "compreensão de que o problema não são os outros, a direita, a mídia ou o próprio governo que pelo visto segue por um caminho conflitante com seus compromissos eleitorais". $\mathrm{Na}$ verdade, daqui por diante, o desafio é superar "a incapacidade da própria esquerda, ou das esquerdas, melhor dizen- 
do, de produzir análises e propostas que sejam capazes de disputar a hegemonia na sociedade e a orientação das políticas de governo". Nessa linha de raciocínio, precisamos de uma ampla coalizão de movimentos sociais e organizações da sociedade civil que possam elaborar análises e propostas superadoras para a construção de um país justo, igual e sustentável. Mas, para tanto, é preciso abraçar bandeiras de transformação social, libertando a indignação e a construção de lutas e esperanças, para enfrentar os mecanismos que garantem os privilégios das elites e a reprodução das desigualdades sociais (Bava, 2015, p. 3).

***

Somado a todo esse quadro conjuntural exposto, essa edição vem a público com os problemas inerentes à produção/veiculação do conhecimento dos periódicos no âmbito das ciências humanas e sociais. Os problemas se agravam no cotidiano da vida acadêmica, principalmente, com a pressão das políticas científicas, que tem como processo/ produto o produtivismo, que engendra o chamado "trabalho intensificado", gerando, assim, o "mal estar docente" ou "mal estar na academia". É nesse limiar que os editores abarrotados de orientações, produção de seus próprios artigos, bancas de mestrado e doutorado, cargos administrativos, reuniões de departamentos e colegiados do PPGE, projetos de iniciação científica, projetos extensão e outros, têm de garantir a periodicidade dos periódicos que editam. Estes são obrigados a produzir suas revistas sob a ameaça de não receber papers à altura de seus projetos editoriais ou acatar textos construídos às pressas sob a égide da "ciência de salame" (Dominguez, 2014; Vilaça; Palma, 2012; Sguissard e Silva Júnior, 2009). São obrigados, muitas vezes, a rejeitar a priori textos que são movidos pela lógica da exacerbação dos modelos calcados na objetividade do conhecimento, na pressa e na quantidade. A consequência disso reside no impasse em não se ter artigos para publicar, principalmente os periódicos avaliados em $\mathrm{B} 4$ e $\mathrm{B} 5$, contra os quais há enormes preconceitos em razão do ranqueamento obtido. Nesse imbróglio, os editores das revistas "qualisficadas" de B2 a B5 se encontram, constantemente, ameaçados de continuarem a "pedirem favor" a intelectuais renomados e reconhecidos, no sentido de amealhar um texto, aqui e acolá, para, assim, poderem sair do alto dos pedestais dos qualis de suas revistas. Como se pode perceber, trata-se de uma avaliação por meritocracia, que se estende também aos PPGEs, cujo processo já vem sendo criticado por diversos intelectuais da ANPED, por exemplo, Vilaça e Palma (2013). Além desses impasses e obstáculos impostos à produção de revistas menos qualisficadas, os editores são impelidos a conviver com outros problemas, tais como: falta de mentalidade acadêmica de alguns setores das universidades sobre o papel das revistas científicas, a escassez de recursos e financiamento, a falta de espaço físico e a falta de infraestrutura em algumas universidades. Some-se a 
tudo isso a falta pessoal técnico qualificado nas bibliotecas e nos programas de pós-graduação para produzir e veicular periódicos com qualidade e relevância acadêmica e social. No entanto, convém destacar que há sinais de alento dessa situação, como a iniciativa Edital n. 001/2014 - FUNAPE/ UFG/MEC/SECADI Processo $n^{0} 10811 / 2014$, cujo objetivo foi "[...] apoiar financeiramente a publicação de periódicos da área da educação classificados como B2, B3 e B4 do atual Qualis Periódicos da Capes da área de Educação.”

As reflexões supramencionadas se justificam, uma vez que, nossos editoriais buscam não apenas fazer meras apresentações óbvias dos textos publicados com resumos e breves comentários, mas fazer breves reflexões sobre o dossiê, os artigos de demanda contínua e demais seções da revista." O objetivo consiste em provocar os leitores a fazerem novas reflexões e sínteses sobre os temas veiculados em cada número, para além dos textos publicados em cada edição.

\section{A atualidade e relevância dos artigos publicados}

Essa edição traz grandes contribuições de pesquisadores reconhecidos pelos seus relevantes aportes teórico-metodológicos e epistemológicos nas ciências humanas e sociais, notadamente, para a área da Educação. São artigos que, de suma atualidade e relevância acadêmico-social, abordam diversas questões, que de tão complexas e multidimensionais parecem se constituir, a nosso ver, em "problemas perenes de pesquisa em educação".

A seção Artigos é inaugurada por Michel Thiollent (UNIGRANRIO), um grande intelectual das ciências sociais, em cuja produção científica se destaca o livro clássico Metodologia da Pesquisa-Ação. Para esse número, o autor nos brinda com um texto sobre a incomum abordagem da literatura articulada com os problemas educacionais, a saber: o Mundo escolar e a literatura em Louis Pergaud. O conteúdo do texto leva em consideração uma leitura de obras literárias de Louis Pergaud (1882-1915), correspondências e informações sobre sua biografia, procurando encontrar sinais da posição crítica do autor, que havia sido professor de ensino primário na região do Jura (França), sobre a educação pública e a pedagogia impositiva de sua época. Tal posição o levou a deixar o mundo escolar de província para tentar a fama literária em Paris no início do século XX. Podendo ser qualificada de libertária, não dogmática, sua posição se expressa principalmente em sua obra mais conhecida, A Guerra dos Botões, e em suas conferências e correspondências. Revela-se uma crítica à concepção do ensino, à pedagogia e aos valores do modelo de escola que estava sendo implantado. Convocado como soldado para a guerra em 1914, Louis Pergaud morreu em combate em 1915, deixando sua obra inacabada. 
O texto de Laure Minassian (Université de Paris VIII - França) traz para o debate um tema de pesquisa hoje já consolidado na ANPED e em linhas de pesquisa de alguns PPGEs: as desigualdades sociais e escolares, cujo enfoque dirige-se às questões do Ensino agrícola com delimitação para a Pedagogia da Alternância na França. De acordo com a autora, os "[...] cursos em alternância são frequentemente invocados para levar ao êxito escolar estudantes fracassados em dispositivos mais convencionais.” Todavia, faz a seguinte questão de pesquisa: mas seus efeitos são aqueles esperados? A pesquisa faz uma análise comparativa entre duas escolas que fazem parte de dois sistemas educacionais de alternância na educação agrícola. A análise comparativa é centrada sobre as produções escritas dos referidos sistemas no início e no final da formação. Os resultados da pesquisa problematizam a crença na eficácia de determinados dispositivos da pedagogia de alternância.

O Conceito de qualidade na educação: articulações e rearticulações nas disputas por hegemonia é o tema proposto por Ricardo Boklis Golbspan e Luís Armando Gandin (URGS). Trata-se de um tema muito discutido, mas que carece de novas reflexões, considerando os equívocos e banalizações que o conceito carrega, dependendo da vertente teórica a que está filiado. $\mathrm{O}$ artigo faz uma análise de como o conceito de qualidade de educação tem sido hegemonicamente definido. Na primeira parte, é apresentado o método de Bakhtin sobre a análise de palavras, para justificar o estudo do conceito de qualidade. Na segunda parte, discute-se como o conceito de qualidade aparece no contexto educacional em função das transformações sociais históricas. Finalmente, contextualiza-se o debate sobre qualidade de educação com as recentes modernizações de Estado.

Senilde Alcântara Guanaes (UNILA), com seu texto Cultura, educação e alteridade numa perspectiva antropológica, busca instigar os leitores sobre as relações entre Antropologia e Educação. Nesse sentido, a autora afirma que Antropologia e Educação são disciplinas próximas em suas origens colonialistas, mas que foram gradualmente distanciadas à medida que os processos culturais, dada a sua dinâmica e intersubjetividade, foram institucionalizando a Educação. Isso se deu, grosso modo, conferindo à Educação a árdua tarefa de sistematizar e transmitir um conjunto específico de saberes, experiências e conhecimentos que servem não apenas à formação do intelecto e do caráter dos indivíduos, mas também à inserção e adaptação destes aos padrões de sociabilidade vigentes. Enquanto isso, coube à Antropologia, de um modo geral, a análise e a compreensão de grupos sociais normalmente divergentes e/ou alheios a tais padrões. O resgate da confluência entre as duas disciplinas, extremamente necessário nos dias atuais, implica em uma reflexão não apenas dos distintos paradigmas que as sustentam, mas também dos seus objetos e campos de atuação, senão comuns, cada vez mais próximos. 
O texto a seguir, cognominado Emotividade versus razão no processo do conhecimento, é de autoria de Balduíno Andreola (URGSe UNISALLE). O autor parte da Filosofia, baseando-se, fundamentalmente, nas contribuições do filósofo existencialista russo Nicolas Berdiaeff, em sua obra Cinco Meditações sobre a Existência, além de buscar interlocuções com outros pensadores, que dedicaram sua luta histórica à construção de outro mundo possível, mais humano e solidário. Assim, ele nos mostra como o Iluminismo, como movimento de ideias, representou grandes avanços, não apenas nos campos filosófico e científico, mas também na educação, na cultura, na política, na economia e no processo histórico de emancipação humana. Todavia, com a absolutização da razão e do indivíduo, desprezando outras dimensões da existência humana, o Iluminismo promoveu o racionalismo, o individualismo, a competição, a especulação capitalista, o colonialismo, a depredação da natureza, guerras sempre mais violentas, aumento das desigualdades, da pobreza, da fome e da violência, a tal ponto que numerosos pensadores caracterizam o mundo atual como a anticivilização da barbárie, e nos desafiam à promoção de outras dimensões do humano, expressas pelas razões do coração.

Joaquín Marín Montín (Universidad de Sevilla - Espanha) apresenta o texto Televisión, educación y deporte. Herramientas para el aprendizaje $\mathrm{O}$ autor argumenta que a televisão tem influenciado decisivamente na configuração do esporte na atualidade, convertendo-se na sua principal fonte de acesso. Nesse sentido, as diferentes disciplinas foram se transformando para poderem adaptar-se a sua captação visual. A realização televisiva tem permitido a aproximação com os aportes técnicos do esporte. Diferentes disciplinas desportivas transformaram-se para poderem adaptar-se à captação audiovisual. A realização televisiva permite abordar aspectos técnicos do esporte que dificilmente poderiam ser apreciados ao vivo. O desenvolvimento tecnológico digital tem revolucionado a recepção das imagens e sons do esporte, aproximando cada vez mais a ação do espectador. Do ponto de vista educativo, as repetições constituem um dos recursos chaves para a análise dos gestos técnicos do esporte. O desenvolvimento de novas técnicas de grafismo baseadas na realidade virtual tem ajudado a compreender novos aspectos do esporte. A integração da televisão com novos meios audiovisuais, como a internet e a telefonia móvel, vem permitindo potencializar a difusão dos valores educativos da atividade física e desportiva.

Outra questão que está na "ordem do dia" das políticas públicas é o ingresso das classes populares na universidade. $\mathrm{O}$ texto $O$ acesso das classes populares ao ensino superior: novas políticas, antigos desafios é de autoria de Thiago Ingrassia Pereira, Fernanda May e Daniel Gutierrez (UFFS). Os autores apontam para o fato de que os percur- 
sos escolares das classes populares no Brasil são permeados por contradições oriundas da desigual estrutura social construída historicamente. Em especial, o ensino superior brasileiro é produto tardio no contexto ocidental, tendo em vista as peculiaridades do processo de colonização, se efetivando nos marcos de uma sociedade que se modernizava em contradição com suas estruturas arcaicas de concentração de poder e prestígio. Um dos resultados mais visíveis deste cenário é a elitização do ensino superior, com sua progressiva "mercadorização". O artigo reflete também sobre aspectos históricos da constituição do ensino superior no Brasil, destacando as políticas públicas de expansão e interiorização ocorridas a partir do início do século XXI. O texto culmina afirmando que "[...] o acesso e a permanência dos segmentos populares nas instituições universitárias se apresentam como grandes desafios a serem compreendidos, contribuindo para um ambiente de reinvenção do próprio conhecimento universitário."

Daniela Andrade Vilaverde e Silva (Universidade do Minho- Portugal) versa sobre a temática Globalização, europeização e educação de adulto: reflexões sobre o Programa Novas Oportunidades em Portugal. Na alvorada do novo milênio, esboçou-se em Portugal uma nova arquitetura na promoção do direito à educação destinada aos adultos: os processos de reconhecimento, validação e certificação de competências (RVCC), desenvolvidos nos Centros Novas Oportunidades (CNO), que conferem aos adultos certificação escolar (B1, B2, B3 e Secundário) e profissional. $\mathrm{O}$ artigo tem como objetivos: a) refletir sobre o fenômeno da globalização, a construção do espaço europeu de educação da União Europeia e as suas influências no sector da educação de adultos em Portugal; b) conhecer as representações dos diretores/coordenadores dos CNO relativamente ao impacto que esses sentiam no tocante às diretrizes emanadas pela União Europeia. Os dados obtidos na investigação denunciam a influência dos processos de globalização no contexto local, confirmando a existência de um determinado grau de porosidade, nesse programa educativo, das normas e diretrizes da União Europeia.

Outro texto traz para o debate as políticas públicas no ensino superior. Trata-se do artigo de autoria de Emanuel Mangueira Carvalho e Silvio Sánchez Gamboa (UNICAMP), cujo título é $O$ estado da arte da produção do conhecimento sobre ações afirmativas nas universidades estaduais paulistas. O intuito da pesquisa é apresentar os resultados de pesquisa sobre as políticas de ações afirmativas com destaque para a construção de um instrumento que ajudou a caracterizar e analisar as teses e as dissertações, localizadas nas bibliotecas digitais das universidades estaduais paulistas, Universidade de São Paulo (USP), Universidade Estadual de Campinas (Unicamp) e Universidade Estadual Paulista "Julho de Mesquita Filho" 
(Unesp), que pesquisaram sobre as ações afirmativas. $\mathrm{O}$ objetivo é responder a duas perguntas, a saber: qual a produção acadêmica da USP, da Unicamp e da Unesp sobre as ações afirmativas? Quais os assuntos pesquisados nas teses e dissertações que tratam sobre as ações afirmativas? Para isso, primeiro foi feito um estado da arte com o objetivo de identificar e caracterizar essas produções. Do total de 209 produções, foram localizadas 30 dissertações e 16 teses, somando 46 trabalhos, sendo 18 dissertações e 7 teses da USP, 7 dissertações e 5 teses da Unicamp, e 5 dissertações e 4 teses da Unesp. O instrumento utilizado nessa análise, denominado de "Mapas Conceituais", foi construído com base no software WebQDA (Web Qualitative Data Analysis), tomando como eixo central o conceito de "ações afirmativas". Com ele foi possível analisar nas teses e nas dissertações localizadas em cada instituição os mapas conceituais relacionados com o eixo central. A análise realizada pelo instrumento constatou que as teses e as dissertações contemplaram diversos conceitos relacionados diretamente com as ações afirmativas, sendo estes Conceitos: o ensino superior no tocante ao acesso, à permanência e ao êxito; as questões relativas à discriminação; os assuntos relativos ao deficiente físico; as questões de gênero e a inclusão social.

Para finalizar a sessão Artigos, Elionaldo Fernandes Julião (UFF) apresenta o texto A educação em espaços de restrição e privação de liberdade no Brasil: perspectivas e concepções. As reflexões são fruto das pesquisas desenvolvidas nos últimos anos sobre a educação para jovens e adultos em situação de restrição e privação de liberdade no Brasil. O artigo procura apresentar algumas reflexões sobre o tema, destacando, principalmente, os aspectos legais, políticos e sociais que envolvem a discussão. Analisando os marcos legais atuais da execução penal brasileira, apresenta a educação como um direito humano fundamental e uma importante política no tratamento penitenciário.

Na seção Entrevistas, os editores realizaram entrevista com Alessandro Pinzani (UFSC), um dos organizadores do livro Vozes do Bolsa Família: Autonomia, Dinheiro e Cidadania (São Paulo: UNESP, 2013). Com essa entrevista, a nossa intenção foi problematizar essa questão, cujo debate é muito complexo e eivado de senso comum tanto na comunidade acadêmica quanto fora dela e na mídia. Foi por essa razão que, considerando a emergência de aprofundamento sobre os limites e possibilidades das políticas públicas e sociais, especificamente, do Programa de Transferência de Renda Bolsa Família, que a Revista lançou algumas perguntas, motivadas pelas ideias contidas no relevante livro Vozes da Bolsa Família: Autonomia, dinheiro e cidadania. O livro aborda uma gama de questões polêmicas e esclarecedoras sobre o Programa Bolsa Família, cujos 
conteúdos são frutos de um exaustivo trabalho de pesquisa qualitativa realizada ao longo de cinco anos (de 2006 a 2011) com mulheres de diversos estados brasileiros. A entrevista foi realizada em 5 de setembro de 2014, a partir do livro organizado por: REGO, Walquiria Leão; PINZANI, Alessandro. Vozes da Bolsa Família: Autonomia, dinheiro e cidadania. São Paulo: UNESP, 2013.

Na seção Caminhos Abertos, Gabriel Carvalho Bungenstab (UFG) e Felipe Quintão de Almeida (UFES) discorrem sobre as relações entre juventude e escola com o texto Os jovens e as tensões do cotidiano escolar. O texto aborda a relação dos(as) jovens estudantes com o cotidiano escolar do ensino médio, numa escola estadual que oferta o ensino médio na cidade de Vitória (ES). Foram realizadas observações no cotidiano escolar durante sete meses e foram aplicados questionários abertos, entrevistas e grupos focais com 130 jovens de quatro turmas de segundo ano, no intuito de saber indícios de como os jovens ser relacionam com os saberes que são produzidos dentro da escola. Conclui-se, com a ajuda das reflexões teóricas do sociólogo polonês Zygmunt Bauman, que há tensões envolvendo a escola, seu corpo pedagógico e os(as) jovens alunos(as).

$$
* * *
$$

A seção Textos Audiovisuais tem como objetivo veicular on-line as diversas linguagens audiovisuais (TICs), visando incrementar o debate sobre as diversas problemáticas da área e buscar estabelecer as relações entre Mídia e Educação e, consequentemente, uma cultura educativa e científica sobre os problemas educacionais cotidianos. Os filmes aqui veiculados podem ser produzidos tanto a partir das diversas experiências educativas realizadas em escolas quanto por grupos e movimentos sociais. Além disso, podem ser sugeridos filmes já disponíveis na internet ou outras mídias. Nesta edição o filme elegido é $A$ Educação Proibida (La Educación Prohibida). Direção: Germán Doin, Argentina, 2012, 115 min. (disponível em: <https://www.youtube.com/watch?v=-t6oGcooBt8>). $A$ Educação Proibida (La Educación Prohibida) é um filme documentário que se propõe questionar as lógicas da escolarização moderna e a forma de entender a educação, visualizando experiências educativas diferentes, não convencionais que colocam a necessidade de um novo paradigma educativo.

Antes de encerrar, fazemos uma nota de destaque sobre o projeto gráfico da capa. A foto foi gentilmente cedida pelo acervo do nosso Centro de Memória do Oeste de Santa Catarina (CEOM), criado em 1986 na Unochapecó, que desde então mantém ações de preservação, valorização e difusão da história e do patrimônio cultural, partindo da concepção crítica da história e da memória e do desejo de inclusão social, visando a garantia de igualdade dos di- 
reitos e do respeito às diferenças culturais. O conteúdo da capa nos remete às memórias das práticas escolares, cuja imagem é da "escoa Mista desdobrada de Linha Fernando Machado" - Cordilheira Alta (SC). Agradecemos ao mestrando do PPGE/Unochapecó, Cristian Cipriani, por ter feito com esmero e sensibilidade a arte final da capa.

Por fim, em "tempos de crise e tempos difíceis", só nos resta reiterar as mensagens de Milton Santos citadas no decorrer do texto: "o mundo não é somente constituído das coisas já feitas, mas de tudo o que é ainda é possível realizar. A História não é apenas o que existe, mas também a soma dos possíveis". Assim, voltamos a repetir um trecho do belo poema de Balduíno Andreola sobre as agruras do produtivismo, na epígrafe que inaugura o editorial:

Dos templos antigos.

Só têm os cientistas

Que amam as listas

De muitos artigos.

Heráclito e Thales.

São sábios sem "qualis"...

Ao qualis e ao lattes,

Prefiro bons mates

Até a próxima edição.

Os Editores

\section{Referências}

ANTUNES, Ricardo. Introdução: A substância da crise. In: MÉSZÁROS, Istivan. A crise estrutural do capital. São Paulo: Boitempo, 2011.

BRAVA, Siovio Caccia. Editorial: A volta às ruas. Lemonde Diplomatique, jan. 2015.

DOMINGUEZ, Bruno. Ciência Salame. Revista Radis 140. Rio de Janeiro: Fiocruz, maio 2014.

MÉSZÁROS, Istivan. A crise estrutural do capital. São Paulo: Boitempo, 2011.

REVISTA RETRATOS DA ESCOLA. CNTE, 2013, Volume 7, Número 12, Dossiê "Avaliação da educação Básica". In: Entrevista com os educadores Heleno Araújo Filho, Luiz Cláudio Costa e Robert Evan Verhine: “Avaliação da Educação Básica”. p. 11-25.

SANTOS, Milton. Avareza, Ano 200o. In: SADER, Emir. 7 Pecados do capital. Rio de Janeiro; São Paulo: Record, 2000. 
SGUISSARDI, Valdemar, SILVA JÚNIOR, João dos Reis. Trabalho intensificado nas federai: Pós Graduação e produtivismo acadêmico. São Paulo: Xamã, 2002.

VILAÇA, Murilo Mariano; PALMA, Alexandre. Diálogo sobre cientometria, mal estar na academia e a polêmica do produtivismo. Revista Brasileira de Educação. Rio de Janeiro: ANPED, Espaço Aberto, 2012. 